Wiaczesław Nowikow

Uniwersytet Łódzki

nowikow_2000@yahoo.com.mx

\title{
Los modos verbales y los inductores modales en las cláusulas subordinadas adjetivas: español vs. polaco
}

\begin{abstract}
Resumen:
En el artículo se analiza la influencia de los inductores modales (características semánticas del antecedente y de los predicados subordinantes, operadores de negación) en la selección de los modos en las cláusulas subordinadas adjetivas en el español actual. Además, se comparan los parámetros de selección modal sintácticos y semánticos en español y polaco. Al final se presentan observaciones sobre las diferencias modales en las cláusulas adjetivas entre las mencionadas lenguas. Por ejemplo, en castellano la selección modal depende, en gran medida, de las propiedades de los inductores modales. En cambio, en polaco es más importante la rentabilidad semántica del modo hipotético, que transmite determinados contenidos modales (no realidad, grado de hipótesis, etc.).
\end{abstract}

Palabras clave: modos verbales, español y polaco, cláusulas subordinadas adjetivas, inductores modales, selección modal

\footnotetext{
Abstract:

Verbal Moods and Modal Triggers in Subordinate Adjective Clauses: Spanish vs. Polish

The aim of this article is to analyze the influence of modal triggers (semantic features of an antecedent and subordinating predicates, as well as negation operators) on the selection of mood in subordinate adjective clauses in contemporary
} 
Spanish. Moreover, the author compares the parameters of modal, syntactic, and semantic selection in Spanish and Polish. He also attempts to make some observations regarding modality differences in subordinate adjective clauses between these two languages. In Spanish, modal selection depends to a great extent on the properties of modal triggers, whereas in Polish, one of the most important factors is the semantic efficiency of hypothetical mood, which transmits certain modal content (no reality, degree of hypothesis, etc.).

Keywords: verbal moods, Spanish and Polish, subordinate adjective clauses, modal inducers, modal selection

\section{Organización sintáctica ${ }^{1}$}

Las cláusulas subordinadas adjetivas desempeñan el papel sintáctico de adyacente o complemento modificador propio de los adjetivos. Las cláusulas en cuestión se ven introducidas por los nexos (pronombres) relativos que, quien, el/la cual, cuyo/a, etc. (de ahí el nombre de relativo), que modifican el núcleo del sintagma nominal de la cláusula subordinante (principal). Este último es sujeto u objeto del verbo de la cláusula principal y desempeña al mismo tiempo el papel de antecedente (ANT; pol. poprzednik o - término lógico-antecedent) del pronombre relativo que, quien, etc., concepto que resulta fundamental para la comprensión del funcionamiento de los modos en las subordinadas adjetivas. De esta manera, el esquema sintáctico de la oración compleja con cláusula subordinada de relativo incluye los siguientes elementos básicos:

Núcleo del SN del PRED subordinante (ANT) + nexo (pronombre relativo) + PRED subordinado (IND/SUBJ)

Por ejemplo:

${ }^{1}$ El presente artículo incluye fragmentos modificados del capítulo escrito por el autor de este estudio y dedicado a los modos verbales que forma parte de la Gramática contrastiva español-polaco, preparada para su publicación por la Editorial de la Universidad de Łódź (colección Manufactura Hispánica Lodziense, 2: Nowikow, W. (ed.), en prensa). 
(1) Me dirijo a los ciudadanos que no han/hayan votado el partido gobernante.

Zwracam się do obywateli, którzy nie glosowali na partię rządzaca.

Dos son las particularidades sintácticas del nexo y del antecedente. El primero puede ir precedido de preposición, p. ej.:

(2) El torneo de tenis lo ganó el chico de quien hablamos la semana pasada.

Turniej tenisowy wygrał chtopak, o którym rozmawialiśmy w zeszłym tygodniu.

En cambio, el segundo puede ser elidido:

(3) Quien bien te quiere, te hará llorar.

Kto cię kocha, ten będzie przyczyna twoich tez (lit. spowoduje, że będziesz płakać).

(4) El que trabaje mucho, aprobará el examen.

Ten kto będzie dużo pracowat, zda egzamin.

(5) Los que no están/estén contentos, que lo digan.

Ci, którzy nie sa zadowoleni, niech to powiedza.

La elisión del antecedente se da, habitualmente, con nexos tales como quien, el que, etc., que marcan a menudo referencias generalizadas.

En cuanto a la organización sintáctica, se observan varias coincidencias entre el español y el polaco. En este último los componentes básicos de la estructura sintáctica en cuestión son prácticamente los mismos. Los nexos que introducen la subordinada son habitualmente pronombres relativos del tipo de który/jaki (esp. que) y kto (esp.quien) (cfr., p. ej., Nagórko, 2005: 159, 307, 311). Al igual que en español, los pronombres relativos polacos establecen una relación correferencial entre el antecedente de la cláusula subordinante y el nexo, el cual, al tiempo que sustituye un elemento nominal, introduce una subordinada (sobre el polaco, véase, p. ej., Grzegorczykowa, 1996: 122-123). Por otra parte, cabe recordar que los nexos prototípicos polacos który i jaki poseen la flexión propia de los elementos nominales, es decir, cuentan 
en su estructura morfológica con morfemas de género, número y caso (p. ej., masc. sing. nominat. który vs. fem. sing. nominat. która; masc. sing. dat. któremu vs. masc. pl. dat. którym). Los morfos de las dos primeras categorías se ven determinados por las características gramaticales del núcleo del SN de la subordinante, mientras que el caso depende de la rección (valencia) del predicado de la cláusula subordinada. Además, al carecer el polaco del artículo, algunas de las formas pronominales mencionadas supra se ven precedidas por pronombres demostrativos ten (esp. este), ta (esp. esta), etc., p. ej., ten, kto zna hiszpański... (esp. el que sabe español).

En español la selección del modo depende básicamente de las propiedades de los elementos que funcionan como inductores modales. Entre estos destaca el llamado antecedente (ANT), cuyo correlato sintáctico es el núcleo del SN de la cláusula subordinante, el cual establece correferencia con el nexo introductor de la subordinada.

\section{Antecedente}

En la mayoría de los estudios el ANT es considerado el factor más importante desde el punto de vista de la selección modal, lo cual quiere decir que la elección del modo depende, en primer lugar, de cómo se enfoquen y presenten las propiedades semánticas del antecedente. El concepto al cual se recurre con frecuencia (véase, p. ej., Fente, Fernández, Feijóo, 1975; Gutiérrez Araus, 2004; NGLE, 2010) al establecer la oposición modal es el de 'especificidad', es decir:

\section{[específico] IND $\neq$ [no específico] SUBJ}

El IND se escoge cuando el antecedente se especifica como algo conocido y concreto para el hablante. En cambio, la selección del SUBJ significa que la cosa o la persona modificada por la subordinada no es suficientemente conocida (o, simplemente, es desconocida) y concreta para el emisor del mensaje o que, en el caso extremo, se refiere a algo inexistente. $C f r$. los siguientes ejemplos: 
(6) Organizaremos un comité que le recibirá/reciba con todos los honores (Fente, Fernández, Feijóo, 1975: 47).

Zorganizujemy komitet, który przyjmie go ze wszystkimi honorami.

(7) El que ha escrito/haya escrito el editorial del periódico de hoy... (NGLE, 2010: 1923).

Ten, kto napisat artykut redakcyjny $\mathrm{w}$ dzisiejszej gazecie...

(8) Apenas hay estudiantes que saben/sepan hablar polaco.

Prawie nie ma studentów którzy potrafia/potrafiliby mówić po polsku.

En los tres ejemplos la elección del IND significa que se trata de personas más bien concretas y conocidas para el hablante, p. ej., los miembros del comité, el autor del editorial o los estudiantes que hablan polaco. A veces conocemos sus nombres y apellidos, a veces sabemos el número de personas a las que nos referimos, etc. El empleo del SUBJ quiere decir que no se trata de personas concretas, que se desconocen su número e identidad (nombre, apellido, etc.). En otras palabras, los antecedentes acompañados de IND tienen carácter específico, mientras que los combinados con SUBJ son inespecíficos. De paso, señalemos que la doble selección es posible con las tres relaciones temporales: anterioridad (7), simultaneidad (8) y posterioridad (6). Anticipando comentarios presentados infra observemos también que no siempre a los dos modos españoles (IND y SUBJ) les corresponden necesariamente dos modos polacos (IND e HIPOT).

Como se ve, el concepto de 'especificidad' se aproxima a la noción de ‘conocimiento’. Así, Veiga (1990: 241-246; 1991: § II.3.1., § II.3.9.) establece la oposición entre indicativo y subjuntivo en función de la dicotomía [conocimiento concreto] IND vs. [conocimiento inconcreto] SUBJ. Cabe subrayar que dichas características son propias de todos los tiempos de los dos modos, lo que no significa que no pueda haber otros rasgos compartidos por algunos de los tiempos de indicativo y subjuntivo. Por ejemplo, en la secuencia (ibidem)

los amigos que en estos momentos están/estarán/estarían/estén/ estuvieran/-sen encantados escuchándome 
los contenidos modales transmitidos por los tiempos del sintagma modificador (los tres primeros indicativos y los dos últimos subjuntivos) se presentan de la siguiente manera:

están conocimiento concreto + no irrealidad + no incertidumbre estarán conocimiento concreto + no irrealidad + incertidumbre estarían conocimiento concreto + irrealidad estén conocimiento inconcreto + no irrealidad estuvieran, - sen conocimiento inconcreto + irrealidad.

Esto quiere decir que en los casos de están, estarán y estarían se trata de amigos concretos y conocidos (sus nombres, número, etc.), mientras que en los de estén y estuvieran/ -sen los amigos referidos no son personas concretamente especificadas. En cambio, las propiedades de '(no) incertidumbre' y de '(no) irrealidad' no son privativas de ninguno de los modos y por lo tanto tienen carácter añadido. Lo que llama la atención es que como adicionales aparecen contenidos que con frecuencia se consideran relevantes para la oposición entre los modos verbales. Este es el caso del contenido modal [ \pm irrealidad], propio tanto del tiempo indicativo estaría como de la forma subjuntiva estuviera/-se. En consonancia, en el caso de las cláusulas subordinadas adjetivas el contenido modal en función del cual se establece la oposición funcional entre los modos en cuestión es [conocimiento \pm concreto].

Hay dos opciones más con respecto a las propiedades modales que permiten establecer la oposición entre los modos según las características semánticas del antecedente. La primera se expresa mediante la fórmula p. ej.:

[experiencia] IND $\neq$ [no experiencia] SUBJ,

(9) Conozco un lugar que es tranquilo (Fente, Fernández, Feijóo, 1975: 46).

Znam miejsce, które jest spokojne. 
(10) Busco un lugar que sea tranquilo (Fente, Fernández, Feijóo, 1975: 46).

Szukam miejsca, które będzie/bytoby spokojne.

La segunda, parecida hasta cierto punto a la primera, se basa en la bipartición

p. ej.:

[existencia] IND $\neq$ [no existencia] SUBJ,

(11) No he hablado jamás con una persona que sea tan sincera.

Nigdy nie rozmawiatem z osoba, która bylaby/jest tak szczera.

(12) No expresa ninguna opinión que no haya sido aprobada por su jefe.

Nie wyraża żadnej opinii, która nie uzyskałaby/uzyskała aprobaty jego szefa.

No obstante, en ambos casos se observa la influencia de elementos externos: verbos con determinadas características semánticas (conocer vs. buscar) u operadores de negación (no, jamás, ninguno). De hecho, por ejemplo, la desaparición de estos últimos provoca la sustitución del SUBJ por el IND:

(13) He hablado con una persona que es muy sincera.

Rozmawiałem z osoba, która jest bardzo szczera.

(14) Siempre expresa opiniones que no han sido aprobadas por su jefe. Zawsze wyraża opinie, które nie uzyskaly aprobaty jego szefa.

Esto quiere decir que, a diferencia de las propiedades atribuidas inherentemente al antecedente, los elementos en cuestión ocupan respecto a este último una posición más bien externa. En los dos últimos casos, en efecto, la selección modal se lleva a cabo en función de las propiedades de los inductores externos.

A continuación, comentaremos la influencia de los operadores de inducción modal presentados supra en la alternancia IND/SUBJ en las cláusulas subordinadas de relativo. Primero, centraremos nuestra 
atención en las características semánticas del predicado de la cláusula subordinante y después haremos una aproximación a los operadores de negación.

\section{Características semánticas del predicado de la cláusula subordinante}

Hay una clase semántica de predicados llamada creadores de contextos opacos (Pérez Saldanya, 1999: 3258-3259), verbos de no existencia (Gutiérrez Araus, 2004: 232-233) o predicados intensionales (NGLE, 2010: 1930-1931), que favorecen el empleo del SUBJ ${ }^{2}$. Nos referimos a verbos tales como, p. ej., buscar, necesitar, que se oponen a predicados de tipo existencial como tener o conocer, que seleccionan con frecuencia el IND. Cfr., p. ej.:

(15) Busco una gramática que me aclare el empleo de los modos en español.

Poszukuje gramatyki, która mi wyjaśni/wyjaśnitaby użycie trybów w hiszpańskim.

(16) Tengo una gramática que me aclara el empleo de los modos en español.

Mam gramatykę, która wyjaśnia mi użycie trybów w hiszpańskim.

Sin embargo, a veces los verbos de no existencia seleccionan el IND, cfr., p. ej.:

(17) Busco una persona que haga [SUBJ] un viaje conmigo.

Szukam osoby, która uda się/udalaby się ze mna w podróż.

${ }^{2}$ Cabe recordar que el término intensional aparece también en los trabajos de varios lingüistas (véase, p. ej., Laca [2015] y [en prensa]), que, al establecer la relación entre ciertas clases de predicados y el SUBJ, distinguen entre los subjuntivos intensionales y los de polaridad. Los primeros se asocian, básicamente, a las construcciones con predicados volitivos y directivos, y poseen, a diferencia de los de polaridad, rasgos tales como, por ejemplo, la no-alternancia con el IND (Te pido que hagas/*haces) o el establecimiento de relaciones de posterioridad o no anterioridad en las subordinadas regidas (Quiero/te pido que lo hagas y lo harás). 
VS.

(18) Busco a una persona que hace [IND] un viaje conmigo.

Szukam osoby, która podróżuje ze mną.

En tales casos se suele señalar (Gutiérrez Araus, 2004: 95) que hay dos marcas de especificidad del antecedente: el IND y la preposición a que antecede el complemento directo de persona específica.

Por otro lado, tampoco la preposición $a$ funciona siempre como marca de especificidad, cfr., p. ej. (NGLE, 2010: 1939):

(19) Busco al médico/a un médico que sea capaz de curarla.

Szukam lekarza, który będzie/bytby w stanie ja wyleczyć.

Como se apunta en la NGLE (2010: 1939), no hay contradicción entre definitud e inespecificidad. En cambio, la diferencia semántica entre este tipo de enunciados se establece a través de la oposición entre el artículo definido, cuyo valor es genérico (se hace referencia a determinada clase de personas), y el artículo indefinido, que presenta a la persona referida como entidad perteneciente a un grupo. Por supuesto, dicha diferencia no se transmite en polaco, cuyo sistema gramatical no cuenta con artículos.

En resumen, hay predicados que por su contenido semántico son, grosso modo, "más existenciales" (tener, conocer, etc.) y hay otros, de carácter "menos existencial" (buscar, necesitar, etc.), cuya realización, subrayemos, nos remite con frecuencia a la posterioridad (Pamies Bertrán, Nowikow, 2015: 73). Los primeros se construyen habitualmente con el IND:

(20) Tengo/leo un artículo en el que se presenta/*presente la situación del español en el mundo de hoy.

Mam/czytam artykut, w którym przedstawia się sytuacja hiszpańskiego w dzisiejszym świecie.

mientras que los segundos, en principio (algunos más, otros menos), admiten tanto el IND como el SUBJ: 
(21) Busco un artículo en el que se presenta/presente la situación del español en el mundo de hoy. Szukam artykutu, w którym przedstawia się/przedstawiono by sytuację hiszpańskiego we wspótczesnym świecie.

En este último caso, en español es el modo el que marca y pone de manifiesto el grado de especificidad o no especificidad del antecedente.

Además, cabe subrayar que, por un lado, los verbos de no existencia demuestran una propiedad bastante universal en cuanto a la selección del modo B (muy frecuente este último en castellano y relativamente regular en polaco $)^{3}$, mientras que, por otro, confirman el funcionamiento asimétrico de los modos en español y polaco: cuando el primero escoge el modo A (IND), también lo hace el segundo; en cambio, cuando el castellano opta más bien por el modo B (SUBJ), el polaco admite tanto el A (IND) como el B (HIP).

\section{Operadores de negación}

Los operadores de negación, generalmente, contribuyen a la selección del SUBJ, si bien no lo hacen de manera obligatoria. Habitualmente, la aparición de este último modo está relacionada con la negación del ANT, es decir, con la no existencia de este. Cfr., p. ej. (Fente, Fernández, Feijóo, 1975: 47):

(22) Tengo algunos amigos que son extranjeros vs. No tengo ningún amigo que sea extranjero.

Mam kilku przyjaciót, którzy sa obcokrajowcami vs. Nie mam żadnego przyjaciela, który bytby/jest obcokrajowcem.

(23) Hay alguien que quiere verte vs. No hay nadie que quiera verte.

3 Se trata de una propiedad semántica cuyas consecuencias modales, hasta cierto punto, son comparables con el comportamiento de los predicados de voluntad (desear/pragnać, querer/chcieć, etc.) e influencia (mandar/rozkazywać, prohibir/zabraniać, etc.), que influyen en la selección del modo B en español y en polaco en las cláusulas subordinadas nominales (véase también supra la nota 2 sobre los predicados y los subjuntivos intensionales). 
Jest ktoś, kto chce cię zobaczyć vs. Nie ma nikogo, kto chciatby/chce cię zobaczyć.

Como se ve, en polaco el HIP sería, quizá, más natural, aunque el IND no es del todo excluible, sobre todo en el registro coloquial de la modalidad hablada. En español la negación del ANT casi siempre provoca el empleo del SUBJ en la subordinada, mientras que el uso del IND es más bien escaso y suele estar condicionado, normalmente, por algún factor adicional, p. ej.:

(24) Ninguno de los que vienen sabe francés vs. Ninguno de los que vengan sabe francés (Fente, Fernández, Feijóo, 1975: 52).

Nikt z tych, którzy przychodza/przyjda/by przyszli zna francuski.

En este ejemplo el empleo del SUBJ está relacionado no solo con el carácter menos específico y/o menos concreto del supuesto antecedente, sino también con la orientación temporal de la acción referida en la subordinada, matizada de posterioridad. En polaco esta diferencia no se marca con tanta regularidad sin que la posterioridad condicione la sustitución del IND por el HIP. En cambio, el posible uso de este último modo matiza la acción de venir como más hipotética y no la presenta como real (aunque no excluye la posibilidad de su realización).

A veces, la negación del ANT se ve, hasta cierto punto, restringida, lo que abre la puerta para el empleo del IND, p. ej.:

(25) Hay pocas personas que saben tanto como él vs. Pocas personas hay que sepan tanto como él (Fente, Fernández, Feijóo, 1975: 52). Jest mało osób, które wiedza tak dużo jak on vs. Mało jest osób, które wiedza/wiedzialyby tak dużo jak on.

En español en la primera oración de hecho se expresa una aserción, es decir, \{hay pocas personas\}, sin que se cuestione la existencia de estas. Esta circunstancia determina el empleo del IND en la subordinada. En cambio, en el segundo ejemplo, al invertir el orden de palabras, se subraya el cuantificador pocas, lo que causa que se haga hincapié en la posible no existencia de las personas en cuestión y, como consecuencia, se favorece el uso del SUBJ. 
El polaco otra vez no delimita con tanta claridad y rigidez los matices modales comentados. El IND es posible en ambos enunciados; el HIP aporta, en el segundo caso, un carácter (¡nomen omen!) más hipotético al hecho referido.

Incluso cuando se trata de selección doble en distribuciones idénticas, como, p. ej., en (Pamies, Nowikow, 2015: 74)

(26) El amor no es una mercancía que se compra o se vende vs. El amor no es una mercancía que se compre o se venda. Miłość nie jest towarem, który się kupuje lub sprzedaje.

la lectura no tiene que ser exactamente la misma. Con el IND se admite que \{hay mercancía que se compra y se vende\}, o sea, hay [aserción] o veracidad del contenido de la subordinada. No obstante, el amor no pertenece a esta clase de mercancía. Con el SUBJ no resulta posible aceptar sin reservas la afirmación de que \{hay una mercancía que se compra y se vende\}. La aserción queda suspendida, puesto que ni se afirma ni se niega la existencia de este tipo de mercancía. Es una distinción muy sutil y, de hecho, resulta difícil establecer diferencias semánticas tajantes entre los antecedentes (además, en ambos casos se trata del sustantivo el amor con características semánticas de generalización y universalidad). En polaco la distinción en cuestión no suele ser marcada al optar habitualmente por el IND, aunque el empleo del modo B no es excluible.

Sin entrar en más detalles, podemos concluir que la selección del modo con los operadores de negación depende, básicamente, del foco de negación (a este respecto véase también Nowikow, 2001: 113-130). Si la negación afecta al ANT (al SN de la cláusula subordinante), el modo elegido suele ser el SUBJ:

(27) No conozco a nadie que pueda/*puede ayudarte (Pérez Saldanya, 1999: 3262).

Nie znam nikogo, kto mógtby/może mu pomóc.

En cambio, si el foco de negación no es el antecedente (el SN de la subordinante) sino, p. ej., el verbo (el SV de la cláusula principal), el modo habitual seleccionado es el IND: 
(28) A la reunión no asistió una persona que conocía/*conociese perfectamente la problemática que debatíamos (Pérez Saldanya, 1999: 3262).

Na zebraniu nie była obecna osoba, która świetnie znata omawiana problematykę.

Una vez más observamos una relación asimétrica en el empleo de los modos polacos. Cuando en español el único modo posible es el B (SUBJ), en polaco se dan ambos modos, es decir, el B (HIP) y el A (IND). En cambio, cuando en castellano la única solución posible es el modo A (IND), también en polaco se opta por el mismo.

\section{Observaciones finales: coincidencias y diferencias}

Para concluir, nuestras observaciones girarán en torno a algunas diferencias en el funcionamiento de los modos verbales españoles y polacos. Lógicamente, vamos a centrar nuestra atención en los criterios de la selección modal.

Las características sintácticas demuestran muchas coincidencias (nexos, relación de correferencia). Las diferencias son, básicamente, de tipo morfosintáctico (la presencia del artículo en los nexos españoles o la expresión morfológica de género, número y caso en los nexos polacos).

En castellano la selección del modo depende, en gran medida, de las propiedades de los llamados inductores modales. En polaco este factor no es tan importante. Destaca, en cambio, la rentabilidad semántica del modo B (HIP) para la transmisión de determinados contenidos (no realidad, grado de hipótesis, etc.).

En español el criterio que influye más en la selección modal es el de las características semánticas del antecedente, es decir: [específico] $\rightarrow$ IND vs. [no específico] $\rightarrow$ SUBJ. En polaco las propiedades semánticas del ANT no son importantes para la elección del modo. Son, en cambio, fundamentales las capacidades semánticas del modo hipotético (HIP). 
Los operadores de negación inducen con mucha frecuencia el SUBJ en las subordinadas adjetivas, lo que confirma la fuerte influencia de este factor, observada también en las cláusulas subordinadas nominales. Cabe subrayar que en polaco este inductor es prácticamente el único que provoca la aparición regular del modo B, es decir del HIP, lo que no excluye, sin embargo, la posibilidad del empleo del IND.

En las subordinadas de relativo españolas, el SUBJ se da a menudo al expresar la relación temporal de posterioridad, lo que se comprueba, entre otros casos, a través de los enunciados (4), (17), (19). En polaco esta distribución no induce necesariamente el modo $\mathrm{B}$, o sea, el hipotético (HIP).

La comparación de la selección modal en español y en polaco demuestra una relación asimétrica. Cuando el castellano opta por el modo A (IND), el polaco también escoge la misma solución (véanse los ejemplos 16, 18, 20). En cambio, cuando el español selecciona el modo B (SUBJ), el polaco admite tanto el modo B (HIP) como el A (IND) (véanse los ejemplos 15, 17, 19).

En general, en las subordinadas adjetivas castellanas se recurre mucho más al modo B, es decir, al SUBJ. Las principales causas de este estado de cosas son la influencia de las propiedades semánticas del antecedente y la contribución de varios inductores modales, entre los que destacan operadores de NEG y predicados de no existencia. El polaco opta más por el modo $\mathrm{A}$, es decir, por el IND, lo que ocurre incluso cuando se admite también el modo B, o sea, el hipotético (HIP).

En cambio, el modo HIP polaco aparece con mayor frecuencia que el SUBJ español en contextos de selección doble, es decir, cuando es posible emplear tanto el modo A como el B y cuando mediante el uso de uno u otro modo se establecen verdaderas diferencias de significado.

Por su parte, el SUBJ español se da con mayor frecuencia en contextos exclusivos, o sea, cuando el empleo del IND no es posible. Esto significa que el uso del SUBJ está condicionado, más que el HIP polaco, por factores sintácticos (se emplea regularmente en determinadas construcciones y depende de determinados elementos gramaticales). No obstante, esto no quiere decir que el SUBJ desempeñe 
casi exclusivamente funciones sintácticas. Como hemos tratado de demostrar en este estudio, el funcionamiento del SUBJ está relacionado con determinadas propiedades semánticas del antecedente y depende al mismo tiempo de las características sintáctico-semánticas de los llamados inductores modales.

\section{Bibliografía}

FENTE, R., FERNÁNDEZ, J., FEIJÓO, L.G. (1975), El subjuntivo, Sociedad General Española de Librería, Madrid.

GRZEGORCZYKOWA, R. (1996), Wykłady z polskiej składni, PWN, Warszawa.

GUTIÉRREZ ARAUS, M. L. (2004), Problemas fundamentales de la gramática del español como 2/L, Arco/Libros, Madrid.

LACA, B. (2015), "On the Temporal Orientation of Intensional Subjunctives in Spanish", en: Guéron, J. (ed.), Sentence and Discourse, Oxford University Press, Oxford, pp. 23-44, [on-line] http://doi.org/10.1093/acprof: oso/9780198739418.003.0002.

LACA, B. (en prensa), "Subjuntivo y concordancia temporal: hacia una estructura de la variación", Moenia, 23.

NAGÓRKO, A. (2005), Zarys gramatyki polskiej, PWN, Warszawa.

NOWIKOW, W. (2001), La alternancia de los modos Indicativo y Subjuntivo en las cláusulas subordinadas sustantivas (metodología del análisis lingüistico), Wydawnictwo Naukowe UAM, Poznań.

NOWIKOW, W. (en prensa), "Modos verbales", en: Nowikow, W. (ed.), Gramática contrastiva español-polaco. 2, Wydawnictwo Uniwersytetu Łódzkiego, Łódź.

PAMIES BERTRÁN, A., NOWIKOW, W. (2015), Los modos verbales en español y en polaco, Wydawnictwo Uniwersytetu Łódzkiego, Łódź.

PÉREZ SALDANYA, M. (1999), "El modo en las subordinadas relativas y adverbiales", en: Bosque, I., Demonte, V. (dirs.), Gramática descriptiva de la lengua española, vol. 2, Real Academia Española/Espasa Calpe, Madrid, pp. 3253-3322. 
Real Academia Española, Asociación de Academias de la Lengua Española (2010), Nueva gramática de la lengua española, t. 1: Morfología/Sintaxis, segunda tirada corregida, Espasa Libros, SLU, Madrid.

VEIGA, A. (1990), "Planteamientos básicos para un análisis funcional de las categorías verbales en español", en: Wotjak, G., Veiga, A. (eds.), $L a$ descripción del verbo español, Verba, 32, Santiago de Compostela, pp. 237-257.

VEIGA, A. (1991), Condicionales, concesivas y modo verbal en español, Verba, Anejo 34, Universidade de Santiago de Compostela, Santiago de Compostela. 